\title{
UM NOVO GÊNERO DE OCHLERINI DO SUL DO BRASIL (HETEROPTERA, PENTATOMIDAE, DISCOCEPHALINAE) ${ }^{1}$
}

\author{
Luiz A. Campos ${ }^{2,3}$ \\ Jocélia Grazia ${ }^{2,4}$
}

\begin{abstract}
A NEW OCHLERINI GENUS FROM SOUTHERN BRAZIL (HETEROPTERA, PENTATOMIDAE, DISCOCEPHALINAE). The new monotypic genus Ocellatocoris and its type species Ocellatocoris dasys, sp. nov. are described from Santa Catarina, Brazil.

KEYWORDS. Ocellatocoris, new genus, new species, Taxonomy.

\section{INTRODUÇÃO}

A análise cladística da tribo Ochlerini, em desenvolvimento, indicou a existência do novo gênero aqui proposto, Ocellatocoris, o qual é considerado o grupo-irmão de Orbatina $^{+}$. O grupo Orbatina ${ }^{+}$é formado pelos gêneros Orbatina Ruckes, 1960, Coranda Rolston, 1992, Schraderia Ruckes, 1959, Ochlerus Spinola, 1837, Stalius Rolston, 1992 e Moncus Stål, 1867.

Foi examinada uma fêmea conservada a seco, depositada no Museu Nacional, Universidade Federal do Rio de Janeiro, Rio de Janeiro (MNRJ). A terminologia das peças da genitália segue Dupuis (1970). As medidas, tomadas a partir da face dorsal das estruturas, estão expressas em milímetros.
\end{abstract}

1. Parte da Tese de Doutorado do primeiro autor. Contribuição n 355 do Departamento de Zoologia da UFRGS.

2. Departamento de Zoologia, Universidade Federal do Rio Grande do Sul; Av. Paulo Gama s/n, CEP 90046-900 Porto Alegre, RS, Brasil. (campos@portoweb.com.br, jocelia@vortex.ufrgs.br)

3. Bolsista FAPESP, processo 96/1328-2.

4. Bolsista CNPq. 


\section{Ocellatocoris gen. nov.}

Etimologia. Do latim ocellatus + coris, referindo-se a um percevejo de olhos de tamanho reduzido. Neutro.

Espécie-tipo. Ocellatocoris dasys, sp. nov.

Cabeça declivosa, ligeiramente mais longa que larga; jugas tão longas quanto o clípeo e convergentes no ápice; margens laterais sinuosas e defletidas, formando um pequeno dente subtriangular na base junto aos olhos. Olhos elevados na região posterior; largura de um olho equivalente a aproximadamente 1/5 da largura da cabeça. Antenas com cinco segmentos, na seguinte proporção: o $1^{\mathrm{o}}$ alcança o ápice das jugas e tem aproximadamente o mesmo comprimento do $2^{\circ}$, que é pouco mais que a metade do $3 \stackrel{\circ}{\circ}$, o mais longo e pouco maior que o $4^{\circ}$, esse aproximadamente igual em comprimento ao 5ㅇ. Búculas arredondadas anteriormente, diminuindo progressivamente na altura em direção posterior, evanescentes no ápice, alcançando a base da cabeça. Origem do 1o artículo rostral anterior à linha transversal imaginária tangente à margem anterior dos olhos; ápice sobre o prosterno. Pronoto declivoso adiante dos ângulos umerais; margem anterior rasamente côncava, margens ântero-laterais suavemente sinuosas, defletidas. Dentículos ântero-laterais pouco proeminentes, dirigidos lateralmente. Escutelo em forma de " $u$ " aberto, quase desprovido de pêlos; margens laterais com uma leve constrição mediana; largura ao nível da constrição equivale a aproximadamente $2 / 3$ da largura basal. Ápice amplamente arredondado, alcançando o ápice do cório, ligeiramente ultrapassando a margem posterior do $5^{\circ}$ segmento do conexivo. Ângulos basais negros, com pequenas fóveas. Hemiélitros não atingindo o ápice do abdome; ângulo apical do cório pouco ultrapassando a margem posterior do 5ㅇ segmento do conexivo. Apice da sutura claval ligeiramente posterior à constrição do escutelo. Membrana com sete ou oito veias longitudinais, não formando células. Prosterno convexo, mesosterno e metasterno planos, percorridos por uma carena longitudinal mediana. Área evaporatória pouco rugosa, ocupando uma estreita faixa semilunar junto à margem posterior da mesopleura, mais larga junto à inserção da mesocoxa; na metapleura, ocupando uma área triangular, que abrange pouco menos da metade posterior do pleurito, com a margem lateral convexa. Peritrema ostiolar auricular, reduzido, não atingindo a margem lateral da área evaporatória metapleural. Tíbias com sulco dorsal raso e largo, delimitado por carenas laterais baixas; superfície lateral externa suavemente sulcada. Terceiro artículo tarsal do terceiro par de pernas sulcado dorsalmente. Conexivo exposto, ângulos pósterolaterais não desenvolvidos. Abdome com um sulco raso longitudinal mediano nos esternitos alcançados pelo rostro. Base do $3^{\circ}$ urosternito desprovida de tubérculo mediano; tricobótrios abdominais externos à linha tangente aos espiráculos.

Genitália ९. Embora os gonocoxitos 8 se encontrem ligeiramente deslocados no holótipo, a aparência dos bordos suturais sugere que esses sejam justapostos, afastados apenas no ápice. Laterotergitos 8 com espiráculo conspícuo junto ao ângulo basal. Gonocoxito 9 triangular com carena longitudinal mediana quase imperceptível. Laterotergitos 9 atingindo a banda que une os laterotergitos 8, margens laterais internas dos laterotergitos 9 em ângulo obtuso, justapostas na metade posterior, ocultando $o$ segmento $\mathrm{X}$, ligeiramente afastadas no $1 / 5$ posterior.

Comentários. Ocellatocoris é considerado o grupo-irmão de Orbatina ${ }^{+}$pela condição do comprimento do escutelo atingindo o nível apical do cório. São autapomorfias 

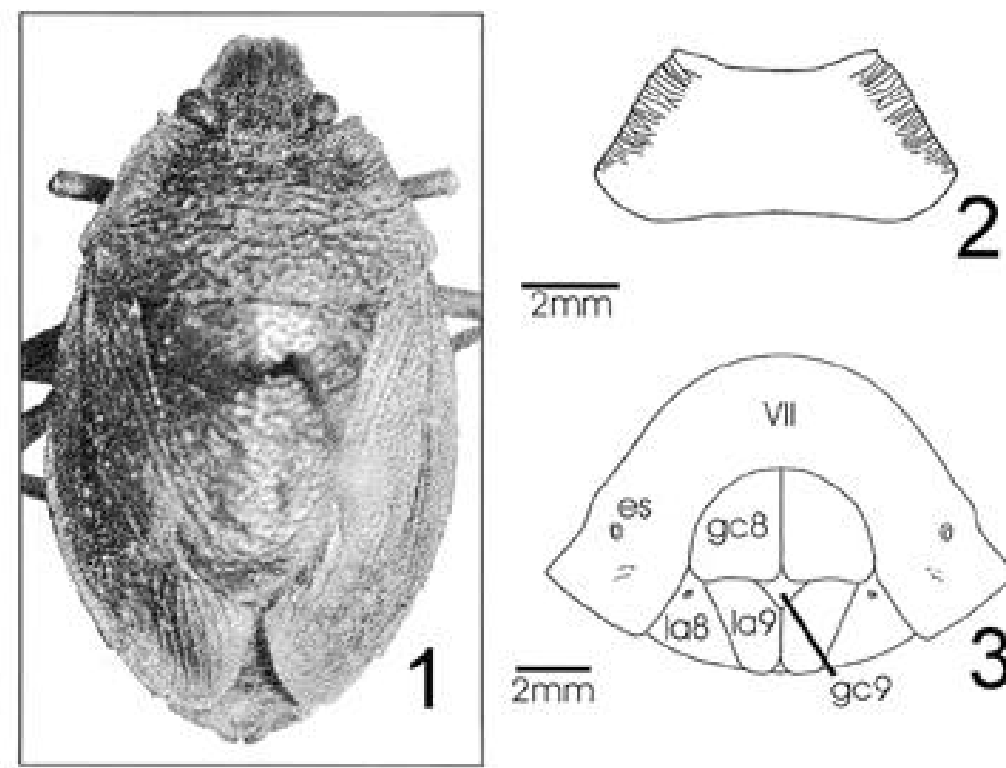

\section{$\overline{2 m m}$}

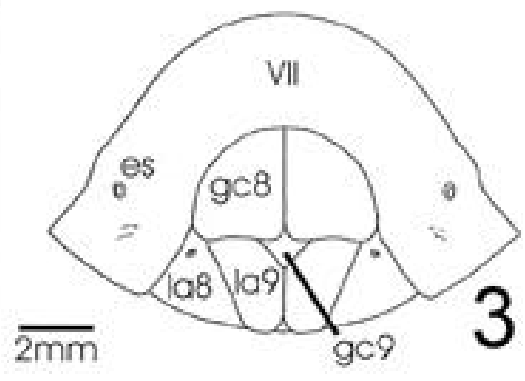

Figs. 1-3. Ocellatocoris dasys, sp. nov., holótipo 9,1 dorsal, comprimento total: 13,4mm; 2, contorno do pronoto, dorsal; 3, placas genitais, ventral (es, espiráculo; gc8, gonocoxito 8; gc9, gonocoxito 9; la8, laterotergito 8; la9, laterotergito 9; VII, sétimo urosternito).

de Ocellatocoris, o tamanho dos olhos, a deflexão das margens ântero-laterais do pronoto, a pilosidade do corpo e a forma das placas genitais.

\section{Ocellatocoris dasys sp. nov.}

(Figs. 1-3)

Localidade-tipo: Corupá, Santa Catarina, Brasil.

Holótipo ९, BRASIL, Santa Catarina, Corupá, II.1952, A. Maller col., Col. C. Seabra (MNRJ).

Diagnose. Coloração geral cúprea, pontuações negras. Corpo recoberto por pêlos, mais densamente na cabeça e na região ventral do abdome. Corpo delineado por uma fina linha negra nas margens ântero-laterais do pronoto, metade anterior do cório e margens do abdome. Membranas dos hemiélitros ligeiramente reduzidas e estreitadas posteriormente.

Descrição (fig. 1). Cabeça densamente pilosa, com pontuações negras, muitas vezes confluentes. Jugas rugosas na metade basal; clípeo convexo na região mediana. Ocelos pequenos, cada um equivalendo a menos que o dobro do diâmetro de uma pontuação, posicionados logo atrás da linha dos olhos. Artículos antenais castanhoclaros, com pêlos uniformemente distribuídos, densidade semelhante à vista na superfície dorsal da cabeça. Rostro castanho-claro; $2^{\circ}$ segmento ultrapassa ligeiramente as mesocoxas, 3o alcança o urosternito III, 4o alcança a margem anterior do urosternito V. Pronoto rugoso, cúpreo, com pontuações grosseiras maiores e mais esparsas que na cabeça, algumas vezes confluentes. Cicatrizes conspícuas, com raras pontuações internas. 
Margens ântero-laterais suavemente crenuladas e finamente delineadas de negro, com numerosas estrias transversais (fig. 2); intumescidas ventralmente. Ângulos umerais arredondados, pouco proeminentes. Escutelo cúpreo quase desprovido de pêlos, com pontuações menos grosseiras que as do pronoto, levemente rugoso junto às margens laterais. Presença de uma pequena mancha amarelada, mediana, irregular, junto à margem anterior. Hemiélitros castanho-cúpreos, pilosidade como no escutelo; pontuações de tamanho equivalente às do escutelo, mais densamente e regularmente distribuídas. Metade anterior da margem lateral externa do cório finamente delineada de negro. Membranas ligeiramente reduzidas, não atingindo o ápice do abdome e estreitadas posteriormente. Pernas castanho-amareladas. Conexivo castanho-escuro, com poucas pontuações rasas e pêlos muito curtos. Abdome ventralmente cúpreo, pontuações rasas castanho-escuras, densamente distribuídas exceto na região central desprovida de pontuações. Pilosidade densa e uniforme; estreita faixa longitudinal nos esternitos III a VI com raros pêlos. Urosternitos III a V com sulco longitudinal mediano raso e com uma faixa marginal castanho-clara com raras pontuações. Margem lateral do abdome finamente delineada de negro.

Genitália $\uparrow$ (fig. 3). Bordo posterior dos gonocoxitos 8 suavemente côncavo; ângulo póstero-lateral externo mais projetado posteriormente que o ângulo sutural. Laterotergitos 8 subtriangulares, com o bordo posterior suavemente convexo, mais projetado posteriormente junto aos laterotergitos 9. Margem lateral externa dos laterotergitos 9 sub-retilínea, ápice arredondado.

Medidas. Cabeça: comprimento 2,7, largura 3,1; comprimento dos artículos antenais: I 0,9 , II 0,9 , III 1,5, IV 1,2, V 1,8; pronoto: comprimento 3,1, largura 2,8; escutelo: comprimento 5,8, largura 4,8; comprimento total 13,4; largura abdominal 8,0.

Agradecimentos. Ao Dr. A. Lago (MNRJ) pelo empréstimo do material.

\section{REFERÊNCIAS BIBLIOGRÁFICAS}

DuPUIS, C. 1970. Heteroptera. In: TuXEN, S. L. ed. Taxonomist's glossary of genitalia of insects. Copenhagen, Munksgaard. p. 190-208.

Recebido em 13.12.1999; aceito em 03.07.2000. 